\title{
Regional X Local Velocity Models Comparison and Evaluation of Possible Impacts for Seismic Imaging
}

Frank Bilhões (Petrobras) ${ }^{*}$, Gleidson Ferreira (Petrobras), Viviane Shimizu (Petrobras), João Batista Boechat (Petrobras), Alexandre Maul (Petrobras), Josué Fonseca (Petrobras), Leonardo Teixeira (Petrobras) \& María González (Emerson)

Copyright 2019, SBGf - Sociedade Brasileira de Geofísica

This paper was prepared for presentation during the $16^{\text {th }}$ International Congress of the Brazilian Geophysical Society held in Rio de Janeiro, Brazil, 19-22 August 2019.

Contents of this paper were reviewed by the Technical Committee of the $16^{\text {th }}$ International Congress of the Brazilian Geophysical Society and do not necessarily represent any position of the SBGf, its officers or members. Electronic reproduction or storage of any part of this paper for commercial purposes without the written consent of the Brazilian Geophysical Society is prohibited.

\section{Abstract}

It is well known the starting velocity model is a crucial aspect when intending to accomplish a good final velocity model through any updating process such as tomographic inversion. It is also well documented the usage of any previous seismic data could help during this updating task. However, it was observed a significant number of projects that extrapolate the previous original data for specific fields, which do suggest the necessity to merge different projects at once. One way to overcome any problem related to the usage of the different projects is to give them a regional aspect, smoothing the model as much possible and preserving the main features. One of the problems by using this approach is the clear understanding that we lost the model details, decreasing the data quality. In this article, it was built a detailed velocity model for a specific project. After that, we compared it with a regional one considering the velocity aspects and limitations, as well as the output seismic (amplitude) information.

\section{Introduction}

For many years, the standard way to build velocity models for depth migration processes was based on the initial velocity fields. After that, it were performed some tomographic inversion updates to get the best alignment over CRP (Common Reflection Points) groups. These initial models could come from previous seismic velocities such as RMS (Root Mean Square) or any prior migration velocity models, calibrating with available well information.

Guo \& Fagin (2002) advocate that the tomographic update only is not a perfect solution for velocity models updating. They emphasized the needed of incorporating a reasonable geological knowledge into any velocity modeling workflow. As per Vigh \& Starr (2008), the FWI (Full WaveForm Inversion) methodology potentially can generate high-resolution velocity models. Those models are currently indicated when using the RTM (Reverse Time Migration) algorithm. However, according to Vigh et al. (2009), one of the main challenges for the FWI technics usage is to produce (or to reproduce) a good starting velocity model to be used to forecast seismic data with geological confidence regarding the subsurface geology, where it has been acquired.
Maul et al. (2013 and previous versions) defend the idea to insert into the interval velocity model all of the relevant geological features observed in previous seismic data, allowing better representation of significant velocity variations. They also advocate the necessity of well calibration using any geostatistical criteria. This approach has been proved as enough for dedicated projects such as mentioned by Pombo et al. (2017).

Bulhões et al. (2014) based on the Maul et al.(2013) have developed a workflow to construct interval velocity models in basin scales, grouping several seismic data acquisitions. Through this approach, the authors have minimized several problems such as data quality, events positioning, etc.

In this paper, it will be presented the first results related with seismic images (processing) adopting both methodologies: the one which looks for the geological details (Maul et al., 2013) and the one which looks for the regional aspect (Bulhões et al., 2014).

Both models were inserted in the same processing step related to the seismic migration. The only aspect that has been varied is the velocity model to produce two seismic images. Those images were then compared, and the results presented.

\section{Method}

The methodology can be described in two parts. In the first one, the structural geological complexity of the area will explain how these features were considered in the velocity model. In the second part, the regional velocity modeling will be explored, describing the steps to build a model in regional scale. Finally, the models will be analyzed and compared.

In the study area, the complexity is due to several Albian carbonate rafts, which lies above an Aptian evaporitic sequence (salt domes and salt windows structures), and both of them above the Pre-Salt (Aptian Carbonates) reservoirs. Besides, regional fault trends in the Post-Salt sequence impose even more complexity for the velocity model. Geological setting with Albian carbonates overburden salt layers, salt top layers with a strong variation in relief and stratified salt layers are collocated with homogeneous halite diapirs that overburden microbial Pre-Salt reservoirs which can cause waveform disturbance (Johann \& Monteiro, 2016).

To build the initial velocity model it was considered an adaptation of the methodology developed by Maul et al., (2013), which tries to represent more geological features into interval velocity models. The assumption here is that interval velocity should minimally reflect of the existing structures portrayed by the interpreted horizons and faults for any interest area.

The regional velocity model for the Campos Basin (Bulhões et al., 2014) has an extension of over 247,000 $\mathrm{km}^{2}$ and cell dimensions of $500 \mathrm{~m} \times 500 \mathrm{~m} \times 50 \mathrm{~m}$. The 
analysis and statistical filtering of velocities by stratigraphic zones were defined by five seismic horizons, interpreted with greater regional continuity. Data simulation requires a representative sample, so the seismic velocities were broken down into six intervals. Each interval was used as a template to simulate velocities in data-poor areas within the same interval. The criteria and ranking of reliability and quality of the data on processing velocities showed that 3D PSDM's were the most reliable and accurate in regions with domes and evaporite bodies.

On the other hand, the 2D PSTM's presented less reliability (Bulhões \& Ferreira, 2018). We applied upper and lower cutoffs to each velocity interval before semivariogram modeling and calibration with well data to remove spurious values (McLean \& Blackburn, 2013; Maul et al., 2013). Velocity points without coherent sedimentary geology upon visual inspection of histograms (below water velocity of $1,450 \mathrm{~m} / \mathrm{s}$ and over $5,000 \mathrm{~m} / \mathrm{s}$ ) we considered erroneous and remove them. This process removed outliers, so they did not bias the simulation process. The seismic velocity adopted for the evaporite layer was $4,500 \mathrm{~m} / \mathrm{s}$ (halite velocity), which represents the mean obtained value from well data (Meneguim et al., 2015; Yamamoto et al., 2016).

In this work, the aim is to investigate if the detail level of information contained in the regional model is comparable to the local model. Therefore, cross-plots of velocity sections were constructed. The mean percentage difference between the regional models was calculated, the average interval velocity maps were also computed for each stratigraphic zone, and the regional maps converted for both models were compared.

\section{Results}

The first evaluation of the two models was accomplished in the Post-Salt portion. Looking at the graphs in figure 1, it is possible to note that in the shallower part, both models are well conformed and that the discrepancy between them increases with depth. To quantify this variation, the percentage difference between both models was calculated (Equation 1), placing the local model as a reference. In figure 2 , the sections with the local, regional and percent difference models are represented.

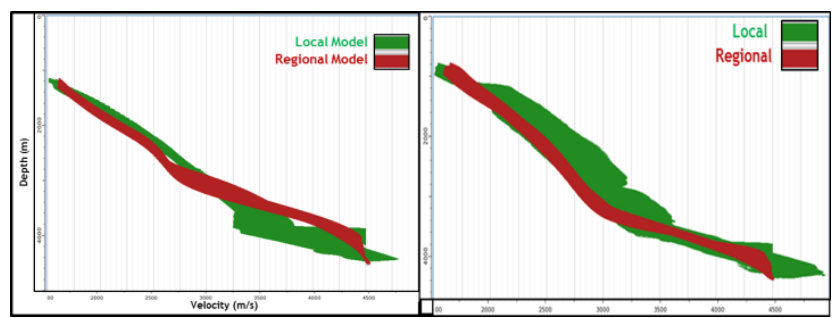

Figure 1: Cross-plot of variation of local (green) and regional (red) models as a function of depth.

$$
\operatorname{dif} f_{\text {perc }}=100 \% \cdot \frac{\left(V_{\text {regional }}-V_{\text {local }}\right)}{V_{\text {local }}}
$$

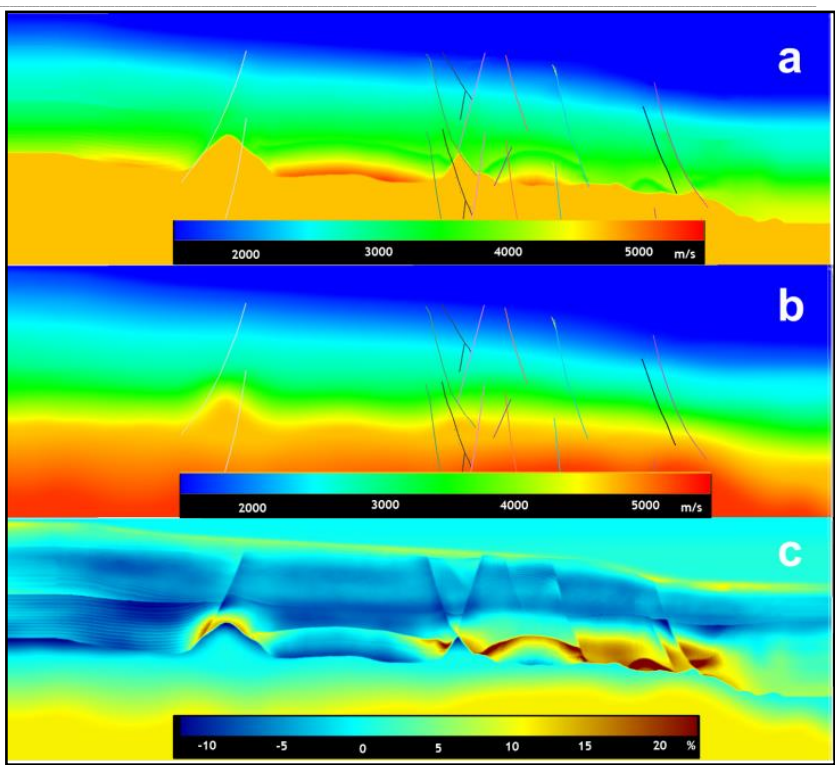

Figure 2: Section with representation (a) local model and (b) regional model and (c) percentage difference.

In figure 3 is the histogram with the distribution of the percentage difference between the models in the PostSalt portion. The average value of this difference is approximately $6 \%$.

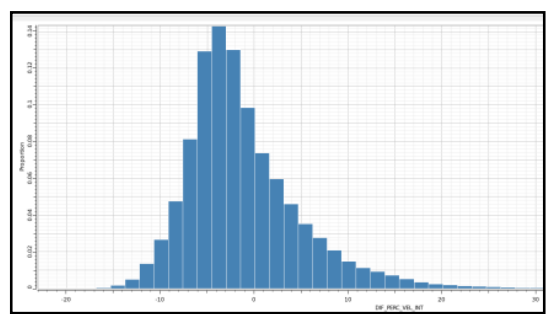

Figure 3: Histogram with the distribution of the mean percentage difference in the Post-Salt portion between the regional and local models.

The evaluation of the maps of average interval velocities is another crucial aspect for comparison between the regional and local models as a function of the stratigraphy. This analysis was carried out in two stages. The first investigates the portion of the Post-Salt as a whole (between Sea Bottom and the Top of Salt). The second stage is to segment the analysis into two stratigraphic zones (Sea-Bottom - Top of Cretaceous, Top of Cretaceous - Top of Salt).

Figure 4 shows the mean interval velocity maps between Sea Floor and Top of Salt of the regional (figure $4 \mathrm{a}$ ) and local (figure 4b) models. A high similarity is observed between the features seen in both maps. 


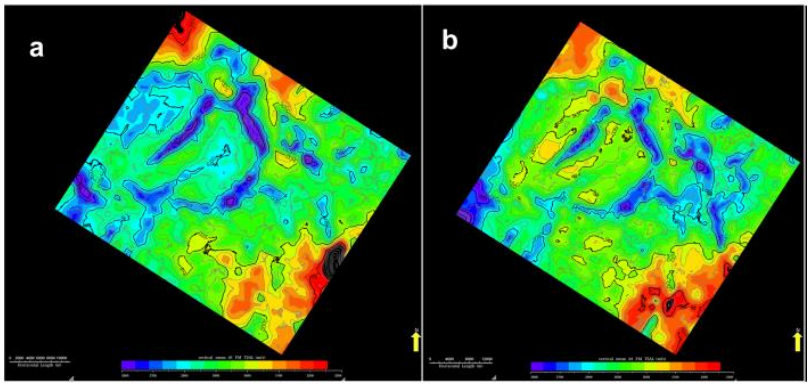

Figure 4: Mean interval velocity maps in the Post-Salt portion of the (a) regional model and (b) local model.

By analyzing the intermediate interval maps in a more detailed way, subdividing into two stratigraphic zones, the differences between both models are more highlighted. Figure 5 shows the mean velocity maps of the shallow stratigraphic zone (Sea Bottom - Top of Cretaceous), where it is possible to observe more substantial discrepancies between the models.

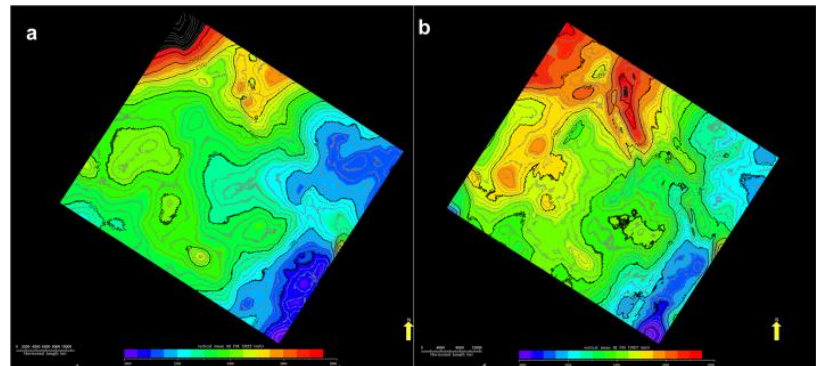

Figure 5: Mean interval velocity maps in the shallow portion of the (a) regional model and (b) local model.

In figure 6 , in the stratigraphic zone between Top of Cretaceous Top and Top of Salt, differences are of greater magnitude. The Albian carbonates present great variability and heterogeneity. In addition, they were not considered in the regional model. The local model presents a greater detail in this section with the velocity variability of the Albian carbonates.

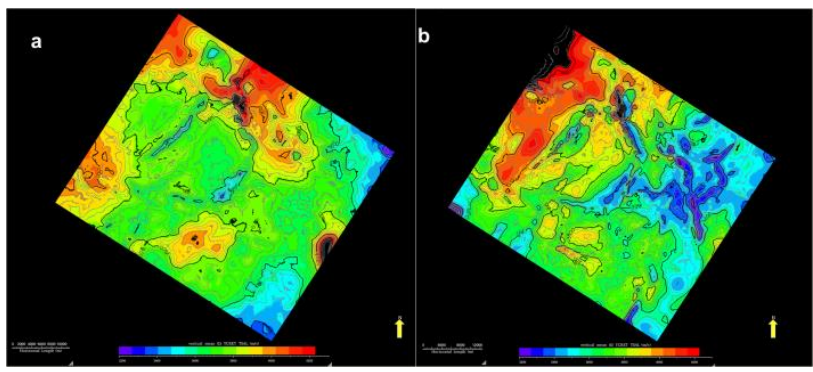

Figure 6: Maps of average interval velocities in the Albian portion of the (a) regional model and (b) local model.

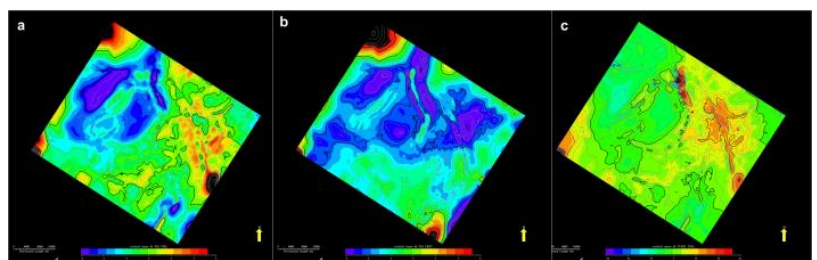

Figure 7: Percentage difference maps between regional and local models for (a) Post-Salt, (b) shallow and (c) Albian.
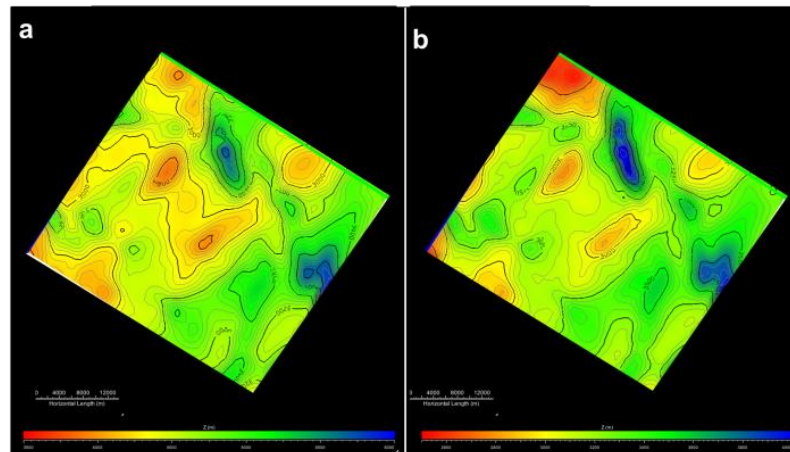

Figure 8: Top of Cretaceous converted by regional (a) and local (b) models. There are no significant differences between the maps obtained in depth.
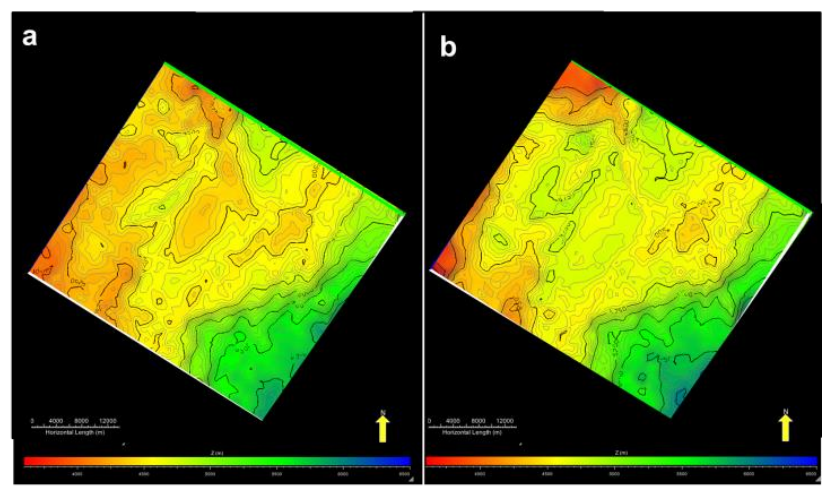

Figure 9: Base of Salt converted by the regional (a) and local (b) models. The differences between the maps are very significant due to the presence of the high heterogeneity in the Aptian microbial carbonates.

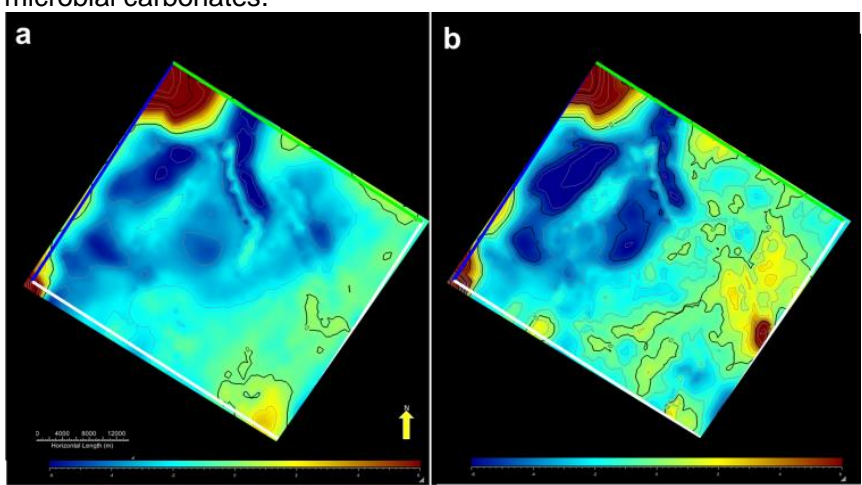

Figure 10: Percentage difference between maps converted by regional and local model (a) Top of Cretaceous and (b) Base of Salt.

\section{Discussions and Conclusions}

The velocity modeling uses the interactions (maps) of the most continuous seismic events. At the regional scale, the Albian carbonates show heterogeneity. This variability is well marked in the local model, more spatially controlled with information of sonic logs and time-depth tables of the wells. This detail is not contemplated in the regional model. Due to this fact, the most significant percentage differences occur in the regional model.

The regional model contributes to gradient information in regions with low heterogeneity and lateral velocity variability. In stratigraphic zones with such complexity (Albian carbonates and evaporite bodies) an initial version 
of the regional model does not contemplate. However, it can be a good model for studies of seismic acquisition where there are only $2 \mathrm{D}$ surveys.

In structurally more complex areas, a higher number of horizons may be required to maintain the velocities control through these structures, preserving structurally consistent velocity gradients.

The regional model is a good initial estimate for structural definition in the subsurface in thicker stratigraphic zones that do not contain large lateral contractions from the conversion of horizons from time to depth. As observed in figure 4, the Post-Salt horizon presents great similarity in macro-structures in both models. However, for the horizon in the Pre-Salt portion, the maps obtained in depth show significant differences (figure 9). These divergences are due to the heterogeneities in the Aptian microbial carbonates that are also not considered in the regional modeling.

Interpretation based on seismic reflection imagery builds on uncertainty arising from limited seismic data resolution, depth conversion error, and human bias. Structural validation techniques have been regarded as one of the most practical approaches to constrain such uncertainty by excluding geologically inconsistent interpretation geometry.

In this work, it was shown that a robust basin-scale velocity model that includes geological constraints in the modeling for time-to-depth conversion presents greater detail in obtaining more consistent geometries of the structural characteristics. Geological resolution constraints largely depends on the distribution of available wells, but even with severe constraints on such coverage, the approach used can be seen as beneficial. An initial velocity model from a regional model with local wellseismic tying and calibrated for well velocities allows for a more consistent agile velocity updating process for local studies. It can also minimize few artifacts, allowing a greater chance of convergence in global minimums for processes of seismic inversion (tomography, FWI).

A future development of this approach will be to incorporate more geological and geophysical constraints, for example, potential field data as well as gravimetric and electromagnetic data. Finally, surveys can provide a broader and more robust resolution for regional velocity models.

\section{Acknowledgments}

The authors would like to thank Petrobras and Emerson for giving the support, time and data for this research, as well as for allowing the publication.

\section{References}

BULHÕES, F.C., AMORIM, G.A.S., BRUNO, V.L.V.R., FERREIRA, G.D., PEREIRA, E.S. \& CASTRO, R.F. 2014. Fluxo para Construção do Modelo de Velocidade Regional da Bacia de Campos. (VI Simpósio Brasileiro de Geofísica). Porto Alegre - RS - Brasil.

BULHÕES, F. C. \& FERREIRA, G. D. 2018. Modelagem Regional De Velocidade Sísmica Das Bacias Marinhas Do Sudeste Brasileiro Para Conversão Tempo-
Profundidade. In I Simpósio Brasileiro de Geologia e Geofísica Marinha. Rio de Janeiro (RJ).

ETRIS, E. L., CRABTREE, N. J. \& DEWAR, J. 2001. True Depth Conversion: More than a pretty picture. CSEG Recorder. 2001.

GUO, N. \& FAGIN, S. 2002. Becoming Effective Velocity Model Builders and Depth Imagers, Part 2 - The Basics of Velocity-Model Building, Examples and Discussions. The Leading Edge, v.21, n.12, p 1210-1216.

JOHANN, P. R. S. \& MONTEIRO, R. C. 2016. Geophysical Reservoir Characterization and Monitoring at Brazilian Pre-Salt Oil Fields. OTC (Offshore Technology Conference), Houston, Texas, USA.

MAUL, A., GOBATTO, F., \& GONZÁLEZ, M. 2013. Modelagem Geológica de Velocidades Sísmica Utilizando - GoCad/SKUA, 2016. (Petrobras Internal Handout Original Version Maul et al., 2005).

MENEGUIM, T.B., MENDES, S.C., MAUL, A.R., FALCÃO, L., GONZÁLEZ, M. \& GONZÁLEZ, G. 2015 Combining seismic facies analysis and well information to guide new interval velocity models for a Pre-Salt study, Santos Basin, Brazil. In 14th International Congress of the Brazilian Geophysical Society 2015, Rio de Janeiro. doi: 10.3997/2214-4609.201412921

POMBO, E., KAZUO, C., FREITAS, F., CARVALHO, A., MAUL, A. \& GONZÁLEZ, M. 2017. Velocity Models Building (Geological and Tomographic Process Updates Emphasis). 15th International Congress of the Brazilian Geophysical Society 2017 - Rio de Janeiro - RJ, Brazil. doi: 10.1190/sbgf2017-349.

VIGH, D. \& STARR, E.W. 2008. 3D Pre-Stack PlaneWave, Full WaveForm Inversion, Geophysics, Vol. 73, No. 5 (September-October, 2008).

VIGH, D., STARR, E.W. \& DINGWALL, K. 2009. 3D PreStack Full WaveForm Inversion, OTC (Offshore Technology Conference), Houston, Texas, USA (OTC 19897).

YAMAMOTO, T., MAUL, A.R., BORN, E., GOBATTO, F., CAMPOS, M.T. \& GONZÁLEZ, M. 2016. Incorporação de Estratificações Salíferas na Modelagem de Velocidade de uma Jazida da Bacia de Santos. In VII Simpósio Brasileiro de Geofísica. Ouro Preto (MG). 